\title{
Designer Core-Shell Nanoparticles as Polymer Foam Cell Nucleating Agents: The Impact of Molecularly Engineered Interfaces
}

\section{Supporting Information}

Shanqiu Liu, Sissi de Beer, Kevin M. Batenburg, Hubert Gojzewski, Joost Duvigneau*, and G. Julius Vancso*

Materials Science and Technology of Polymers, MESA+ Institute for Nanotechnology, University of Twente, P.O. Box 217, 7500AE, Enschede, the Netherlands.

Materials Science and Technology of Polymers, MESA+ Institute for Nanotechnology, University of Twente, P.O. Box 217, 7500AE, Enschede, the Netherlands.

Corresponding authors: j.duvigneau@utwente.nl (J. Duvigneau); g.j.vancso@utwente.nl (G. J. Vancso) 


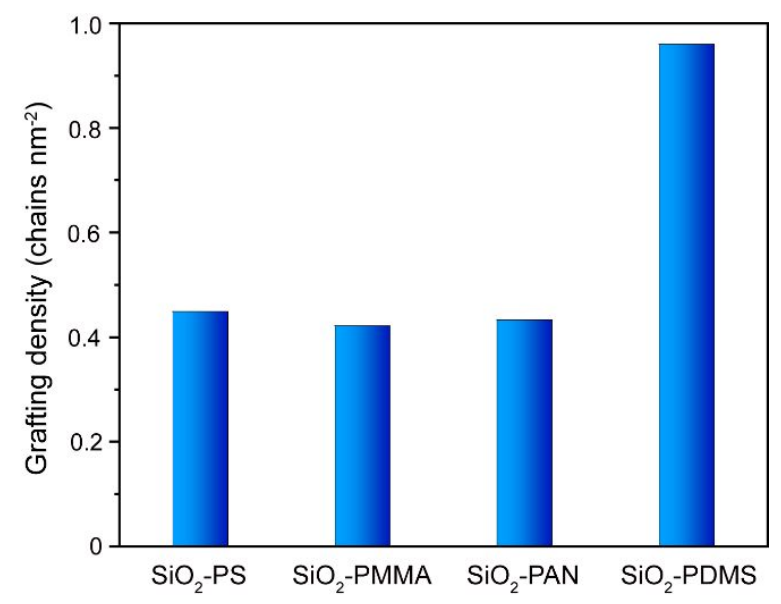

Figure S1. Grafting density of polymer chains obtained for different core-shell nanoparticles.

Based on the TGA results, the molar mass (measured by GPC) of grafted PS (5,500 $\mathrm{g}$ mol-1), PMMA (7,100 $\left.\mathrm{g} \mathrm{mol}^{-1}\right)$ PAN $\left(9,060 \mathrm{~g} \mathrm{~mol}^{-1}\right)$ and PDMS (1,000 $\left.\mathrm{g} \mathrm{mol}^{-1}\right)$ polymer chains as well as the surface area of the used $\mathrm{SiO}_{2}$ nanoparticles $\left(33 \mathrm{~m}^{2} \mathrm{~g}^{-1}\right)$, the grafting density of PS, PMMA, PAN and PDMS were calculated, and the results are shown in Figure S1.

The grafting densities (D) of polymer chains are calculated according to equation S1:

$$
\mathrm{D}=\frac{\mathrm{A} *\left(\frac{\mathrm{m}}{\mathrm{M}}\right)}{S}
$$


Where $\mathrm{A}$ is the Avogadro constant $\left(\mathrm{A}=6.02 * 10^{23}\right)$. $\mathrm{m}$ is the weight of polymer chains grafted on $1 \mathrm{~g}$ silica nanoparticles. $\mathrm{M}$ is the molar mass of the polymer chains. $\mathrm{S}$ is the surface area of $1 \mathrm{~g}$ silica nanoparticles.

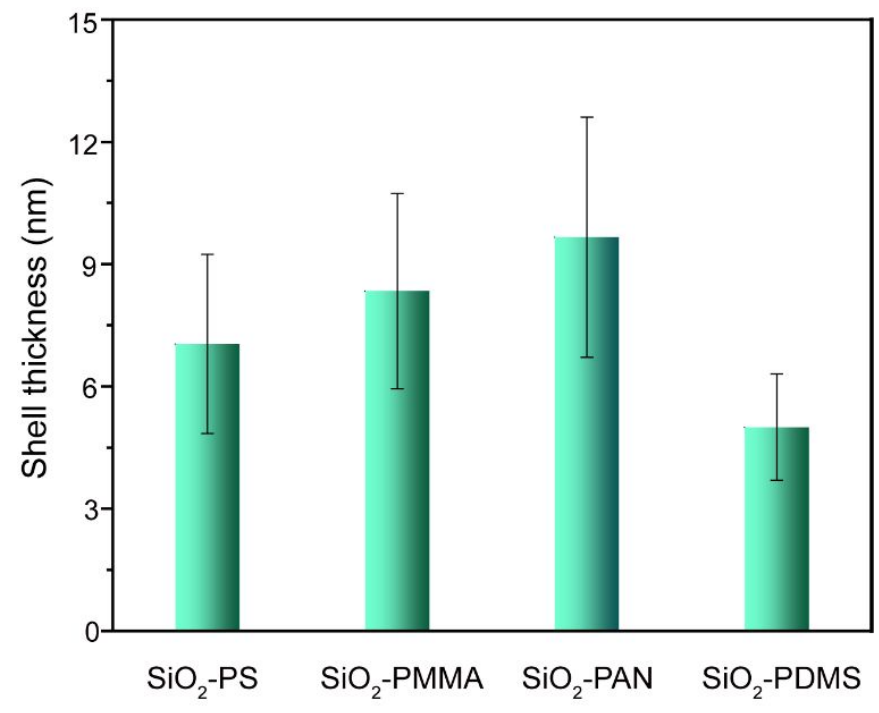

Figure S2. Polymer shell thickness of different core-shell nanoparticles.

From TEM results (see Figure 2), the shell thickness values of different core-shell nanoparticles were estimated, and the results are shown in Figure S2. 

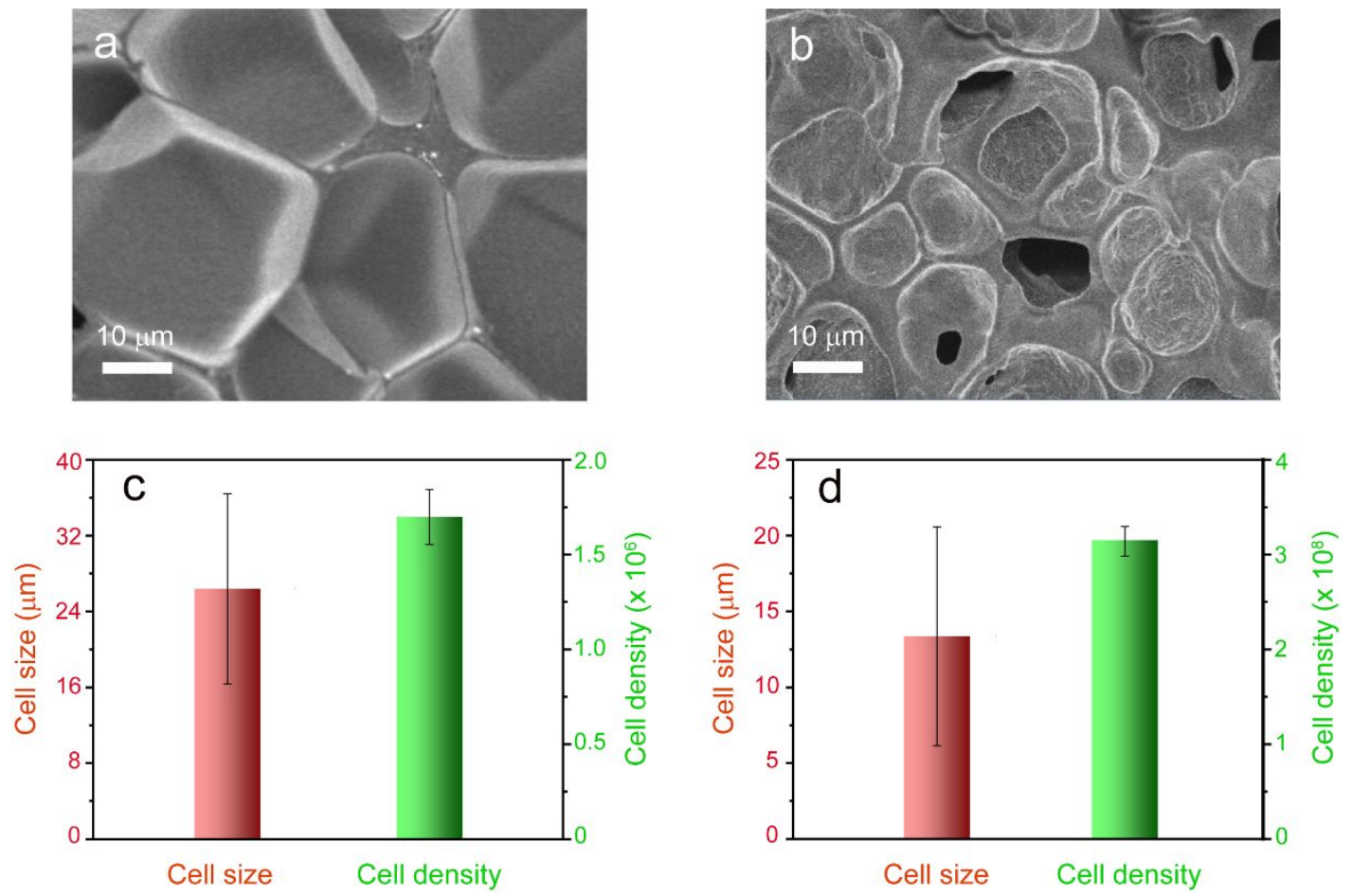

Figure S3. SEM images showing the microstructures of the cross-sectioned (a) PS and (b) PMMA foams containing no nanoparticles. Cell size and cell density of (c) PS and (d) PMMA foams without nanoparticles.

Figure S3 shows the foam microstructures, cell size and cell density obtained for PS and PMMA foams containing no nanoparticles.
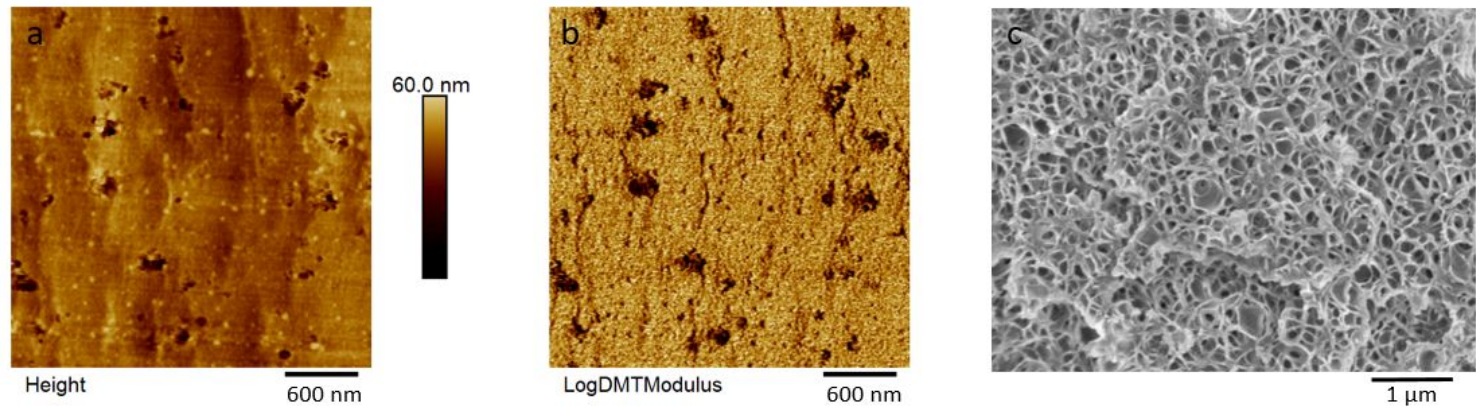

Figure S4. Peak force tapping atomic force microscopy (AFM) height (a) and Log DMT modulus (b) images of a cryo-microtomed film of PMMA extrusion blended with $10 \mathrm{wt} \%$ 
PMMA-PDMS-PMMA. The AFM images clearly reveal PMMA-PDMS-PMMA triblock copolymer domains in the PMMA matrix. In (c) a SEM image of the corresponding foam is shown.

Figure S4 shows AFM peak force tapping mode height (a) and LogDMT modulus (b) images of a cryo-microtomed film of PMMA (V925T, Arkema) blended with a PMMAPDMS $_{10}$-PMMA triblock copolymer $(10 \mathrm{wt} \%)$. The PDMS domain density was $1.8 \pm 0.1 \times$ $10^{14} \mathrm{~cm}^{-3}$. Following batch foaming $\left(\mathrm{P}_{\text {sat }} 55\right.$ bar for 4 hours and $\mathrm{T}_{\text {foam }} 80^{\circ} \mathrm{C}$ for 2 minutes $)$ the resulting foam had a foam cell density of $2.0 \pm 0.4 \times 10^{14} \mathrm{~cm}^{-3}$. This points to a close to unity nucleation efficiency for the phase separated PDMS domains. We note that the PMMA used for this experiment was different compared to PMMA used in the main manuscript, which explains the different used foaming conditions.
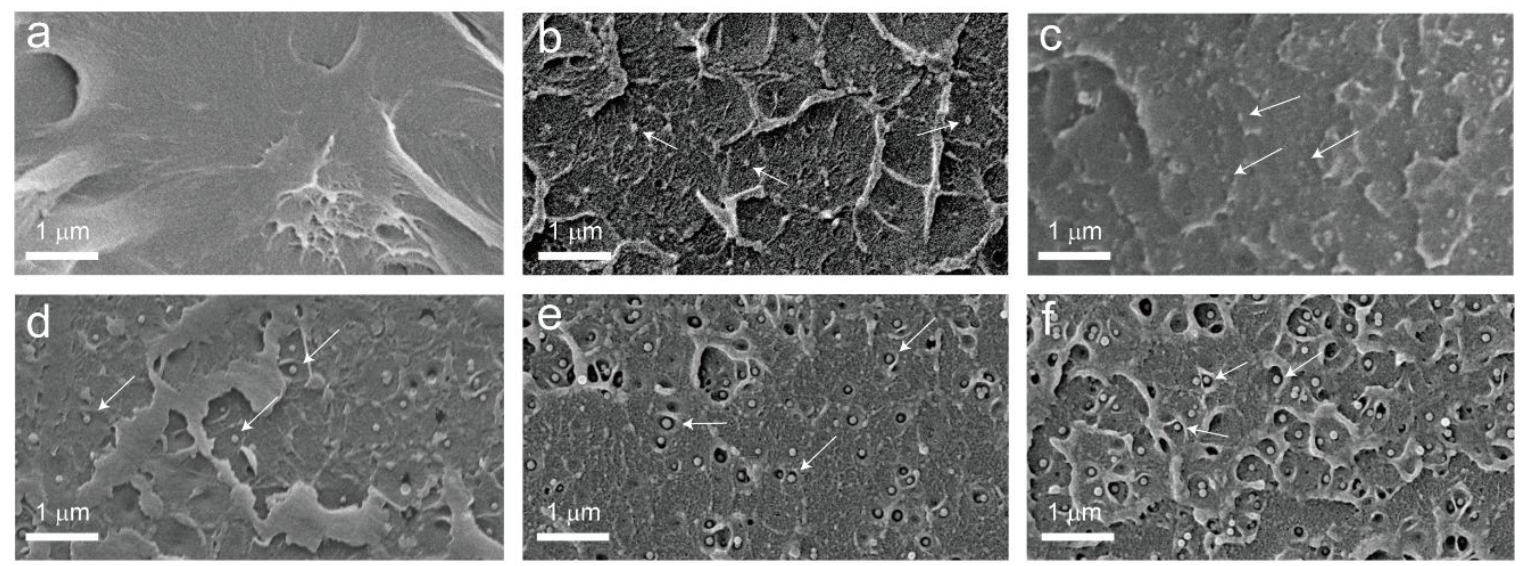

Figure S5. Cross-sectional SEM images of PMMA with (a) no particles, (b) bare $\mathrm{SiO}_{2}$, (c) $\mathrm{SiO}_{2}-\mathrm{PMMA}$, (d) $\mathrm{SiO}_{2}-\mathrm{PS}$, (e) $\mathrm{SiO}_{2}-\mathrm{PAN}$ and (f) $\mathrm{SiO}_{2}-\mathrm{PDMS}$. 


\section{Pressure Valve}

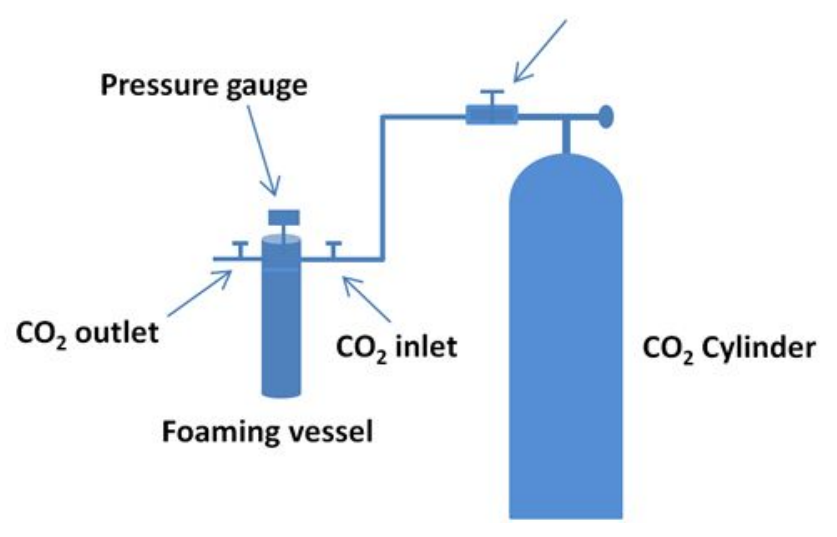

Figure S6. Scheme of the used batch foaming setup. 